\title{
A saphenous vein graft aneurysm nineteen years after aortocoronary bypass graft surgery: from diagnosis to reoperation
}

\author{
Zoran Miovski*, \\ Miroslav Krpan, \\ Bojan Biočina, \\ Joško Bulum \\ University of Zagreb School \\ of Medicine, University \\ Hospital Centre Zagreb, \\ Zagreb, Croatia
}

KEYWORDS: bypass aneurysm, reoperation, late postoperative complication. CITATION: Cardiol Croat. 2016;11(3-4):114. | Dol: http://dx.doi.org/10.15836/ccar2016.114

*ADDRESS FOR CORRESPONDENCE: Zoran Miovski, Klinički bolnički centar Zagreb, Kišpatićeva 12, HR-10000 Zagreb, Croatia. / Phone: +385-98-464-811 / E-mail: miovski.zoran@gmail.com ORCID: Zoran Miovski, http://orcid.org/0000-0002-385 • Miroslav Krpan, http://orcid.org/0000-0002-0639-953X Bojan Biočina, http://orcid.org/0000-0003-3362-9596 • Joško Bulum, http://orcid.org/0000-0002-1482-6503

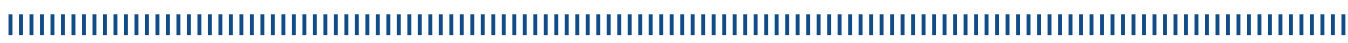

Introduction: Giant aneurysm of the saphenous vein grafts (SVG) is a rare complication of coronary artery bypass surgery, with an overall incidence of $<1 \%{ }^{1}$. SVG aneurysms are often asymptomatic, incidentally identified by imaging modality; there are reports of aneurysm rupture, fistula formation and hemodynamic compromise resulting from compression of adjacent cardiac and vascular structures.

Case report: We present a case of a 73-year old patient who was admitted to our Clinic with complaint of dizziness and fatigue. He denied having any chest pain or shortness of breath. Nineteen years ago he suffered an inferior myocardial infarction and had surgical myocardial revascularization - aortocoronary bypass surgery with (SVG) on left anterior descending artery (LAD) and right coronary artery (RCA) with no postoperative complications. During actual hospitalization his ECG showed sinus bradycardia. Chest x-ray revealed a nodular infiltrate close to the right side of the heart raising suspicion of intrathoracic tumorous mass. Echocardiography confirmed the presence of paracardial anisoechogenic mass measuring 10x7 cm with partial compression of the right atrium. Color Doppler view of the mass showed pulsatile flow in part of the mass and urgent computerized tomography with intravenous contrast of the thorax and abdomen was performed showing aneurysm of the SVG on right coronary artery with preserved flow mimicking intrathoracic tumor. Coronary angiogram expectedly showed chronic total occlusion of LAD and RCA and patent SVGs with gigantic aneurysmatic dilatation of the RCA SVG and significant stenosis in proximal part of the LAD SVG. Few months later the patient was admitted to surgery, a large aneurysm of venous graft was found with thrombus burden. RCA was bypassed with a new venous graft and reconstruction of venous graft to LAD was done. Fifteen days after operation, patient was discharged to a local hospital.

Conclusion: Because of its high potential for morbidity and mortality, we should treat this complication adequately. Due to better follow-up and increasing use of diagnostics, more patients with SVG aneurysms will be identified. SVG aneurysms have been generally treated by surgical repair, although percutaneus endovascular methods can be used ${ }^{2}$.
RECEIVED:

February 9, 2016

ACCEPTED:

February 20, 2016

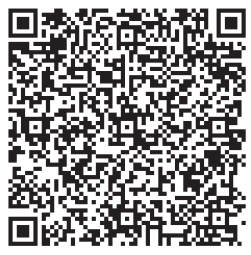

口 Cardiologia Croatica 2016;11(3-4):114.

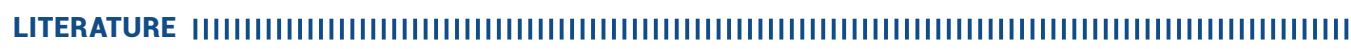

1. Ramirez FD, Hibbert B, Simard T, Pourdjabbar A, Wilson KR, Hibbert R, et al. Natural history and management of aortocoronary saphenous vein graft aneurysms: a systematic review of published cases. Circulation. 2012;126(18):2248-56.

DOI: $h$ ttp://dx.doi.org/10.1161/CIRCULATIONAHA.112.101592

2. Katoh H, Nozue T, Michishita I. A case of giant saphenous vein graft aneurysm successfully treated with catheter intervention. Catheter Cardiovasc Interv. 2016;87(1):83-9. DOI: http://dx.doi.org/10.1002/ccd.25984 